\title{
MEDIATING ROLE OF BEHAVIORAL BIASES BETWEEN EMOTIONAL INTELLIGENCE AND FINANCIAL DECISION MAKING: A CONCEPTUAL FRAMEWORK
}

\author{
MUSKAAN ARORA \& SANTHA KUMARI \\ Chitkara Business School, Chitkara University, Punjab, India \\ School of Humanities and Social Sciences, Thapar University, Patiala, India
}

\begin{abstract}
Stock market Participation and risk preferences are the two most crucial aspects of personal financial decision making of the investors. Several studies have indicated that emotional intelligence affects the investors 'behavioral biases, stock preferences, and risk tolerance. However, researchers have not found any study exploring the underlying path through which emotional intelligence is related to stock market participation. Consequently, a mediational study was carried out to examine whether behavioral biases and risk preferences function as a connection between investors' emotional intelligence and stock preference. The results of the study showed that people with low emotional intelligence show less stock market participation and prefer fewer risks in their financial decisions than people with high emotional intelligence. Moreover, risk preferences and also behavioral biases such as loss aversion, regret and also risk preferences were found to be mediators the effect of emotional intelligence on stock market participation of the investors.
\end{abstract}

KEYWORDS: Emotional Intelligence, Behavioral Biases, Stock Preference and Risk Preference

JEL Codes: D03, D81, G02, Behavioral Finance

Received: Jun 08, 2020; Accepted: Jun 28, 2020; Published: Sep 15, 2020; Paper Id.: IJMPERDJUN20201244

\section{INTRODUCTION}

Personal financial management can be stated as managing the investments of the individuals for accomplishing their own financial goals. The handling of personal money is imperative for financial wellbeing of the individuals.

When managing personal finances, the investor should find the suitability of a variety of banking products or stock market investments, bonds and mutual funds and insurance products for his or her needs.Stock market participation is one of the crucial decisions in personal financial decision making. Increasing uncertainty along with stockmarket crash in 2008 in India crushed the morale of the investors to invest in stocks. Therefore, it is importunate to find out the causes why people refrain to invest in stocks. Lot of researches was carried out pertaining to stock market participation which suggested various factors such as risk aversion, behavioral biases(Ngoc, 2014; Dimmock 2005) and also psychological abilities such as emotional intelligence(Ameriks et al., 2009) affects stock market participation. Following are few of the studies related to the above statement.

\section{REVIEW OF LITERATURE}

Risk Tolerance and Stock Preferences

Laakso (2010) studied stock ownership drivers and reported that there are various determinants such as life 
satisfaction, sociability, confidence, political orientation, risk aversion, religion and cognitive abilities clearly explain stock market participation. Prior Literature also indicated that difference in risk preferences is the actual cause for all variances across individuals' portfolio composition (Merton, 1969).

\section{Psychological Factors on Stock Market Participation}

Previous researches have suggested that varied aspects' of personal decision making is influenced by emotional intelligence. Each emotion affects risky decisions in a distinct way. Individual becomes risk averse with fear while he becomes risk seeker with anger. (Lerner \& Keltner 2000). Ameriks et.al (2009) reported that the psychological factor such as emotional intelligence influence the decision of investors to buy stocks and also affects the level of transactional activity.

\section{Behavioral Biases on Stock Market Participation}

Previous literature suggested that risk preferences are affected by various behavioral biases. Chin (2012) investigated Malaysian stock market investors and found that their investment decision making is influenced by psychological biases named as regret, beliefs and self-confidence. Dimmock (2005) indicated that the more loss-aversive individuals participate and invest less in risky assets. The effects of aversion to Myopia and Loss on risk perceptions are different. Investors who show aversion to myopic loss may take greater risk if they review their assets less often. (Thaler, Tversky, Kahneman $\&$ Schwartz, 1997).

\section{The Present Study}

From the above literature it is clear that risk aversion, behavioral biases and psychological characteristics are the key determinants of the shareholding of investors in the stock market. However, earlier studies concentrated on single factor at one point of time while investigating the drivers for participation of investors in stocks market. The present study will explore the effect of a number of variables such as emotional intelligence, risk preferences and behavioral biases together on investors' stocks holdings. In addition, the researchers have not found any study exploring the underlying path through which emotional intelligence is related stock market participation. The objective of this research is to explore whether the relationship of emotional intelligence and investors' participation in the stocks is influenced indirectly through behavioral biases and risk preference. Mediation analyses have been worked out for each of independent psychological variables. Based on the prior literature following proposed model has been formulated as shown in Figure 1(A).

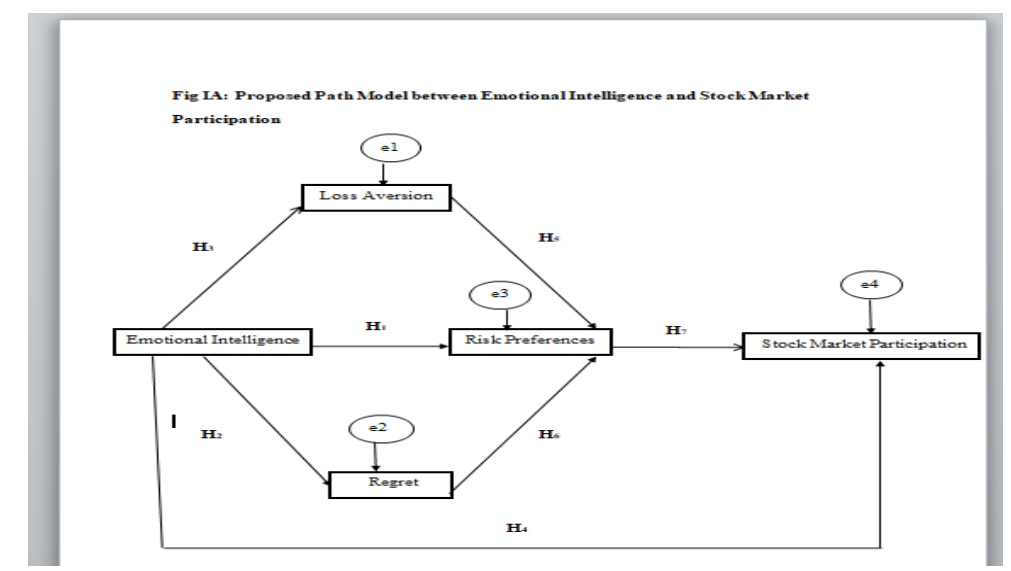

Figure 1 


\section{Based on the Model I (A) the Following Hypotheses have been Formulated}

$\mathrm{H}_{1}$ : There is significant positive relationship between emotional intelligence and risk preferences of the investors.

$\mathrm{H}_{2}$ : There is significant negative relationship between emotional intelligence and regret.

$\mathrm{H}_{3}$ : There is significant negative relationship between emotional intelligence and loss aversion.

$\mathrm{H}_{4}$ : There is significant positive relationship between emotional intelligence and stockmarket participation of the investors

$\mathrm{H}_{5}$ : There is significant negative relationship between loss aversion andrisk preferences of the investors.

$\mathrm{H}_{6}$ : There is significant negative relationship between regret and risk preferences of the investors

$\mathrm{H}_{7}$ : There is significant positive relationship between risk preferences and stock market participation of the investors

$\mathrm{H}_{8}$ : Loss aversion, Regret and Risk preferencehave a mediatorrole between the emotional intelligence and stock market participation of the investors.

\section{RESEARCH METHODS}

For collecting the data from investors' survey approach was applied in this research. The present paper used a questionnaire and standardized test to gather data from the selected sample and Software AMOS 20 was used to carry out the SEM that is structural equation modeling for testing the hypotheses of the proposed model. It provides various fit indices for models such as CFI (comparative fit indices)GFI (goodness of fit) and others to determine fitness of the proposed model.

\section{Sample}

The target group was 396 males of northern part of India of the age of 25-40 years with education of graduation and above and their average monthly income was Rs. 25000-80000.Teachers, businessmen and various financial experts volunteered to participate in the study

\section{Design}

The mediating variables are loss aversion and regret and risk preferences while stock market participation is the final outcome variable and emotional intelligence is the predictor variable. The path coefficients for all variables were found by conducting mediational analysis.

\section{Tools Used}

- TeiQUE: Emotional Intelligence was measured by Trait emotional Intelligence Questionnaire developed by Petrides and Furnham (2006). The questionnaire consists of four subscales of wellness, self-control, emotionality and sociability with total of 30 items. The score for emotional intelligence (EI) is formed by adding raw scores of each subscale. 
- GAMA: All individuals' cognitive ability was assessed by General Adult Capability Measurement which is a standardized test developed by Naglieri and Bardos (1997). It is composed of 66 questions, divided into four subscales which are construction, matching, sequence and analogies.

- Loss Aversion: It was measured by using a modified version of lottery choice task developed by Gachter, Johnson and Hermann (2010) which was originally developed by Fehr and Goette (2007). Individuals must decide whether to accept a sure result or a lottery (Appendix A). Loss aversion was determined by switching point for investors to pick the lottery from a sure outcome. The higher the switch point, the higher the aversion for the loss of the subject.

- $\quad$ Regret: It was determined by providing the investors a regret inducing scenario which was derived from Ratner $\&$ Herbst (2005). They have to take a decision to select one of the brokers between A and Bto invest Rs. 50000 for the period of one year. Post the selection of the broker, they were told that the broker or the dealer selected by you got failed and does not give the promised results after one year. In this scenario they have to assess their own decision whether their decision for selecting the chosen broker by them was right or wrong. This decision was administered to assess the degree of regret the investors experienced by using regret scale developed by Connor, 1996 (Appendix B).

- Stock Market Participation: This research used a self-made questionnaire consisting of four questions with 5 options in each item in order to deduce the information about the investment of the subject in equities or stock, (Appendix C).

- Risk Preference: Similar to stock market participation, a self-designed questionnaire was formed to assess the investors' capacity to take risks. The questionnaire consists of six statements with five options in each statement. The subject has to select one of the best options out of five options presented in each question (Appendix D).

\section{RESULTS}

\section{Correlation}

Correlation was computed between all variables studied. The finding of present study found that the emotional intelligence is significantly correlated with loss aversion $(\mathrm{r}=-.131,404)$ and regret $(\mathrm{r}=-.191,404)$, stock market participation $(\mathrm{r}=.182$, 404) and risk preferences $(r=.168,404)$ of the investors. Furthermore, risk preference and behavioral biases were also found to be the predictors of stock market participation. It was also found risk preferences ( $\mathrm{r}=.302$, 404) were significantly correlated with stock market participation. In addition, both loss aversion and regret $(\mathrm{r}=-.121,404)(\mathrm{r}=-.164,404)$ respectively are negatively correlated with stock market participation.

\section{Mediation Analysis}

Maximum likelihood method was used in the present study to determine the estimates of various variables. Mean and standard deviation of exogenous variables such as emotional intelligence and also of endogenous variables such as regret, loss aversion, preference for stocks and preference for risk are displayed in Table I. Table II presents the estimates and standard errors of the different variables. 


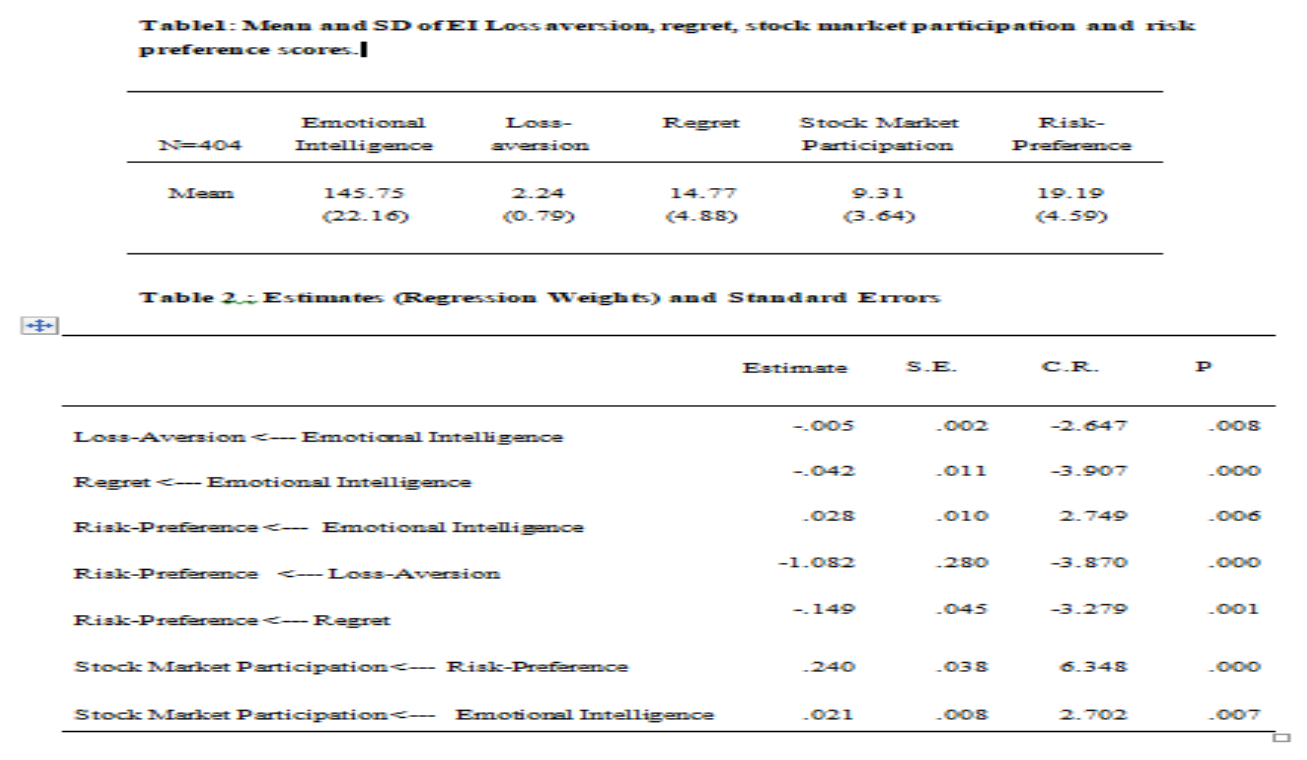

Figure 2

\section{Path Analysis Results}

All the proposed hypotheses confirmed in the model. Emotional intelligence was found to be positively related to risk preferences $\left(\mathrm{H}_{1}: \beta=.028, \mathrm{p}<0.01\right)$ and negatively related to regret $\left(\mathrm{H}_{2}: \beta=-.042, \mathrm{p}<0.001\right)$ as well as loss aversion $\left(\mathrm{H}_{3}: \beta\right.$ $=-.005, \mathrm{p}<0.01)$ respectively. Furthermore, loss aversion and regret was found to be negatively related with risk preferences $\left(\mathrm{H}_{5}: \beta=-1.08, \mathrm{p}<0.001 ; \mathrm{H}_{6}: \beta=-.143, \mathrm{p}<0.01\right)$ respectively and risk preferences positively affects investors participation in stock market $\left(\mathrm{H}_{7}: \beta=.240, \mathrm{p}<0.001\right)$.

The default model II B fits the data $\left(\mathrm{X}^{2} / \mathrm{df}=2.173\right.$, GFI=.993 CFI=.966, NFI=0.943, RMSEA=0.054). The present study confirmed that emotional intelligence affects stock market participation both directly $\left(\mathrm{H}_{4}: \beta=.02, \mathrm{p}<0.01\right)$ and indirectly $\left(\mathrm{H}_{8}: \beta=.09, \mathrm{p}<0.001\right)$ through risk preferences and behavioral biases (loss aversion, regret). Fig. I B shows loss version, regret and risk preferences functions as mediators between emotional intelligence and investors' participation in the stock market. A bias 95\% confidence intervals (CI) bootstrap [.004,.017]further reconfirmed the indirect influence of emotional intelligence on stock market participation.

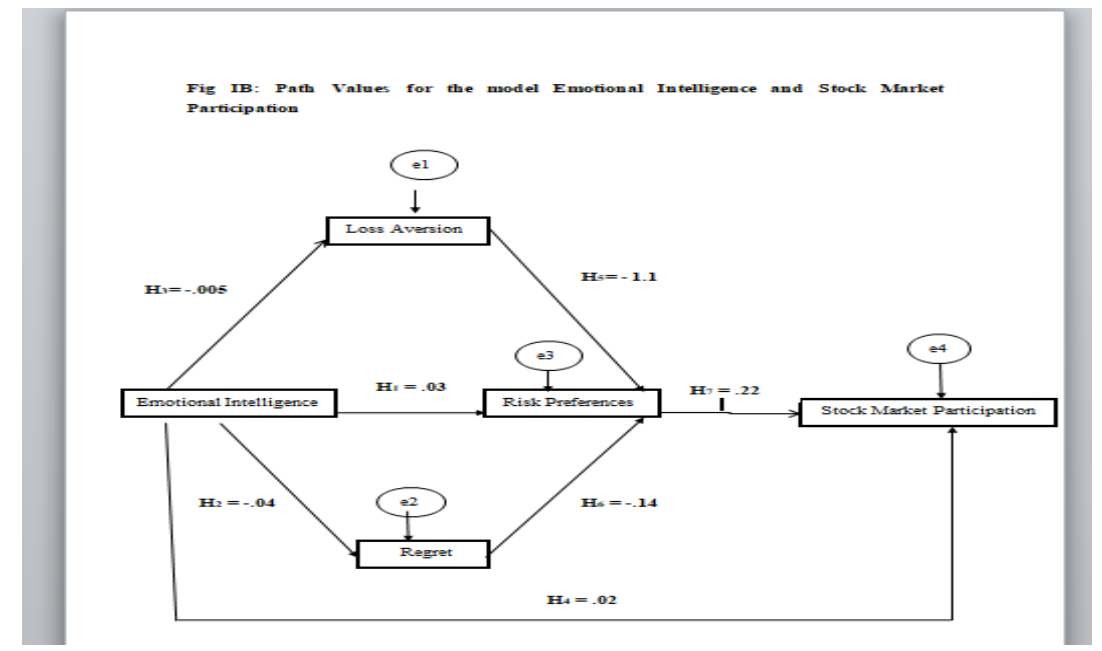

Figure 3 


\section{DISCUSSIONS}

The researcher examined the effect of emotional intelligence on investors' behavioral biases, shareholding and risk tolerance. The findings of this research confirmed the proposed hypotheses $\left(\mathrm{H}_{2}\right.$ and $\left.\mathrm{H}_{3}\right)$. Figure 1B indicates that emotional intelligence is negatively related with behavioral biases, suggesting that high emotionally intelligent individuals show less aversion towards regret and loss in comparison to low emotionally intelligent individuals. Emotional intelligence of CEOs was negatively correlated with loss aversion while it was positively correlated with optimism and overconfidence (Azouzi \& Jarboui, 2013). The outcomes of this study are congruous consistent with the above mentioned study that suggested that the relationship of emotional intelligence with behavioral biases is negative. A possible reason for this result is that people with a high degree of emotional intelligence are more outward-oriented, emotionally secure and robust (Md Nawi \& Redzuan, 2011).

As predicted, the results of the present study also showed that financial decisions are functions of emotional intelligence. The decisions involving uncertainty and risk are affected by emotions (Loewenstein et.al.,2001). Ameriks et.al., (2009) suggested that emotional intelligence and personality attributes play crucial role in investment decision making. They reported that people with low EI were less aggressive and more conservative in their risk preferences as in comparison to people with high EI. The finding of this research is in accordant with the previous research that emotional intelligence is positively correlated to risk tolerance and participation in the stocks $\left(\mathrm{H}_{1}\right.$ and $\left.\mathrm{H}_{4}\right)$. High emotionally intelligent individuals have more shareholdings and prefer more risks in their investments in comparison to low emotionally intelligent individuals.

Additionally, the hypotheses $\left(\mathrm{H}_{5}, \mathrm{H}_{6}\right.$ and $\left.\mathrm{H}_{7}\right)$ that behavioral biases are in negative relation to risk preferences and also that risk preferences are in positive relation with stock market participation were confirmed. These results agree with previous work on behavioral biases and risk tolerance. They reported that investors respond differently to earlier profits/losses. Earlier profits enhance risk taking of the investors whereas previous losses decline the risk taking of the investors (Massa \& Simonov, 2002).

Moreover, the findings of the mediation analysis also indicate that all factors such as emotional intelligence indirectly influence investors' shareholdings via loss aversion, regret and risk preferences $\left(\mathrm{H}_{8}\right)$. The results of this research suggested that people with low emotional intelligence are more inclined to loss aversion and regret, and these behavioral biases such as loss aversion and regret decreases the investors' risk preferences, which further reduces their investor's shareholdings.

\section{SIGNIFICANCE OF THE STUDY}

The study's findings provide practical as well as theoretical implications. The investment industry along with financial advisors, planners should not take all of its investors in the same homogeneous groups and should take these differences into account while making investment decisions for its investors. Alternatively, each investor's psychological attributes should be taken into account by the investment industry individually and applied this information when designing the portfolio to achieve the investors ' financial goals. In addition, practitioners, researchers and family economists should design and suggest financial products based on each investor's profile and his personality attributes. Furthermore, the present study will help investors to understand and overcome their biases to maximize their profits. Moreover, it will also help investors to take portfolio decisions and understand the variables that influence their decision making. Regulatory 
bodies such as the Securities Exchange Board of India will improve the growth of the stock market by providing various sessions to financial service providers such as banks, advisory firms, asset management companies and others pertaining to psychological determinants of personal financial decisions. Finally, these results will increase the predictive power of the financial models with respect to an individual's psychological characteristics, which can contribute to successful financial decisions. Institutional investors, financial planners, lay investors, stockbrokers and others who manage and utilizewealth advisory services to make investment decisions will certainly be interested in these findings of the present study.

\section{CONCLUSIONS}

On a final note, this research can be said to be groundbreaking because it adds to the literature in such a way that it simultaneously explores a wide variety of key determinants of investors' shareholdings (risk preferences behavioral biases and emotional intelligence). Furthermore, the present research also identifies the paths through which these factors are related to investors' participation in shares market. To the best of the researchers' knowledge, this research is the first of its kind to uncover the mechanism and path by which emotional intelligence and behavioral biases influence stock market participation.

\section{REFERENCES}

1. Ameriks, J., Wranik, T. and Salovey, P. 2009, 'Emotional intelligence and investmentbehavior',Retrievedfromhttp://www.cof.cg/dbdata/attachments/\%5B4add84845d86a\%5DEmotional Intelligence and investor behavior.pdf.

2. Azouzi, M.A and Jarboui, A. 2013, 'CEO Emotional Intelligence and Firms' Financial Policies Bayesian Network Method', Contemporary Economics, Vol. 8, pp.5-24.

3. Chin, A.L.L. 2012, 'Psychological Biases and Investor Behavior: Survey Evidence from Malaysian stock Market, International Journal on Social Science Economics.

4. Dimmock, S.G 2005, 'Loss aversion and Household Portfolio Choice, Retrieved from https://www.google.co.in/?gfe_rd=cr\&ei=N7Y8VOOUBajV8gfJu4DYCg\&gws_rd=ssl\#q=Dimmock\%2C+S.G+(2005).+Loss + aversion+and + Household + Portfolio+Choice.

5. Fehr, E., L. Goette. 2007, 'Do workers work more if wages are high? Evidence from a randomized field experiment', American Economic Review, Vol. 97 No.1, pp.298-317.

6. Gachter, S., Johnson, J.E., \& Herrmann, A. 2010, 'Individual-level loss aversion in riskless and risky choices', CEDEX Discussion Papers 2010-20, Centre for Decision Research and Experimental Economics

7. Laakso, E 2010, 'Stock market participation and household characteristics in Europe, School of Economics Aalto University.

8. Lerner, J and Keltner, D 2001, 'Fear, Anger, and Risk', Journal of Personality and Social Psychology, Vol. 81, No. 1, pp. 146159.

9. Loewenstein, G, Weber, EU, Hsee, CK and Welch, N 2001, 'Risk as feelings', Psychological Bulletin, Vol. 127, pp. 267-286.

10. Massa, M and Simonov, A 2005, 'Behavioural Biases and Investment, Review of Finance, Vol. 9, pp. 483-507.

11. Merton, RC 1969, 'Lifetime Portfolio Selection under Uncertainty: The ContinuousTime Case', The Review of Economics and Statistics, Vol. 51, No. 3, pp. 247.

12. Naglieri, J.A. \& Bardos, A.N. (1997). General Ability Measure for Adults. Minneapolis, MN: National computer systems 
13. Nawi, NHM and Redzuan, M 2011, 'Emotional Intelligence, Personality and Self Esteem: A Comparison of the Characteristics among Two Categories of Subjects. International Journal of Humanities and Social Science, 1(8), 238-247.

14. Ngoc, L.T.B., (2014). Behavior Pattern of Individual Investors in Stock Market. International Journal of Business and Management; 9 (1), 1-16.

15. O' Connor, A.M. 1996, 'User Manual - Decision Regret Scale', Retrieved from http://decisionaid.ohri.ca/docs/develop/User_Manuals/UM_Regret_Scale.pdf

16. Petrides, K. V. and Furnham, A. 2006, 'The role of trait emotional intelligence in a gender-specific model of organizational variables', Journal of Applied Social Psychology, Vol. 36, pp.552-569.

17. Ratner, R.K. and Herbst, K.C. 2005, 'When good decisions have bad outcomes: The impact of affect on switching behaviour', Organizational Behavior and Human Decision Processes, Vol. 96, pp. 23-37.

18. Thaler, HR, Tversky, A, Kahneman, D, and Schwartz, A. 1997, 'The effect of myopia and loss aversion on risk taking, 'The Quarterly Journal of Economics, Vol. 112, No. 2, pp. 647-661. 